\title{
Aberrant DNA methylation of cancer-related genes in giant breast fibroadenoma: a case report
}

\author{
Diego M Marzese ${ }^{1,2}$, Francisco E Gago ${ }^{2,3}$, Javier I Orozco ${ }^{2,3}$, Olga M Tello ${ }^{3}$, María Roqué ${ }^{1}$ and \\ Laura M Vargas-Roig $2,4^{*}$
}

\begin{abstract}
Introduction: Giant fibroadenoma is an uncommon variant of benign breast lesions. Aberrant methylation of CpG islands in promoter regions is known to be involved in the silencing of genes (for example, tumor-suppressor genes) and appears to be an early event in the etiology of breast carcinogenesis. Only hypermethylation of p16INK4a has been reported in non-giant breast fibroadenoma. In this particular case, there are no previously published data on epigenetic alterations in giant fibroadenomas. Our previous results, based on the analysis of 49 cancer-related CpG islands have confirmed that the aberrant methylation is specific to malignant breast tumors and that it is completely absent in normal breast tissue and breast fibroadenomas.
\end{abstract}

Case presentation: A 13-year-old Hispanic girl was referred after she had noted a progressive development of a mass in her left breast. On physical examination, a $10 \times 10 \mathrm{~cm}$ lump was detected and axillary lymph nodes were not enlarged. After surgical removal the lump was diagnosed as a giant fibroadenoma. Because of the high growth rate of this benign tumor, we decided to analyze the methylation status of $49 \mathrm{CpG}$ islands related to cell growth control. We have identified the methylation of five cancer-related CpG islands in the giant fibroadenoma tissue: ESR1, MGMT, WT-1, BRCA2 and CD44.

Conclusion: In this case report we show for the first time the methylation analysis of a giant fibroadenoma. The detection of methylation of these five cancer-related regions indicates substantial epigenomic differences with non-giant fibroadenomas. Epigenetic alterations could explain the higher growth rate of this tumor. Our data contribute to the growing knowledge of aberrant methylation in breast diseases. In this particular case, there exist no previous data regarding the role of methylation in giant fibroadenomas, considered by definition as a benign breast lesion.

\section{Introduction}

Fibroadenoma represents the most frequent breast lesion in adolescents and young women with the giant fibroadenoma (GF) being an uncommon variant. GFs, which occur mostly in adolescent girls, are characterized by their large size (more than $5 \mathrm{~cm}$ ). They are encapsulated masses and generally asymptomatic. Their rapid growth (between two and five months) is associated with skin congestion and ocasionally ulceration. It is

\footnotetext{
* Correspondence: vargas!@mendoza-conicet.gob.ar

${ }^{2}$ School of Medical Sciences, National University of Cuyo, Parque General San Martín s/n, CP 5500, Mendoza, Argentina

Full list of author information is available at the end of the article
}

thought that increased estrogen receptor sensitivity is responsible for the etiology of GF [1].

Aberrant methylation of $\mathrm{CpG}$ islands (CpGIs) in promoter regions is known to be involved in the silencing of tumor-suppressor genes, steroid receptors, cell adhesion molecules and cell cycle regulator genes and appears to be an early event in the etiology of breast carcinogenesis [2]. The aberrant methylation of cell cycle regulator genes leads to a higher proliferation rate [3].

Our previous results, based on the analysis of 49 cancer-related CpGIs, have confirmed that the aberrant methylation is specific to malignant breast tumors and that it is completely absent in normal breast tissue and breast fibroadenomas [4]. Other authors have reported 
aberrant methylation of p16INK4a not only in malignant breast lesions but also in fibroadenoma and normal mammary tissues [5]. There are no previous data of epigenetic alterations in giant fibroadenomas. The established precursors of breast carcinoma are atypical ductal hyperplasia, ductal carcinoma in situ, and lobular neoplasia. The malignant transformation of a fibroadenoma is a rare event, with about 100 cases reported in the world literature. Despite this fact we decided to analyze the methylation status of a GF which is a rapidly growing benign breast lesion [6], because the methylation of the analyzed genes is associated with a greater capacity for cell growth [3].

\section{Case presentation}

A 13-year-old Hispanic girl was referred after she had noted the progressive development of a mass in her left breast. On physical examination, a $10 \times 10 \mathrm{~cm}$ lump was detected. Her axillary lymph nodes were not enlarged. Surgery was performed and a GF was removed. At present, with a follow-up of three years, both breasts are symmetrical, normally developed, and no signs of recurrence have been detected at clinical evaluations.

Methylation-specific multiplex ligation-dependent probe amplification (MS-MLPA) assay was performed on the DNA obtained from the GF to study the methylation status of the 49 CpGIs (Table 1). We have previously analyzed these regions in invasive ductal carcinomas, breast fibroadenomas and normal mammary tissue [4]. The MS-MLPA Kits ME001 and ME002 were used according to the manufacturer's recommendations (MRC-Holland, Amsterdam, Netherlands) with minimal modifications [4].

The immunohistochemical procedure was performed as reported previously using the monoclonal antibody clone ER88 (Biogenex, CA, USA) against estrogen receptor alpha protein [7].
We have detected aberrant methylation in five cancerrelated CpGIs, that is estrogen receptor- $\alpha$ [ESR1 (+244bp)], O6-methylguanine-DNA methyltransferase [MGMT (-463bp)], Wilms' Tumor-1 [WT-1 (-146bp)], Breast Cancer 2 [BRCA2 (+138bp)] and Hermen Antigen [CD44 (+28bp)] (Figure 1). As a control we have analyzed six normal breast tissues and three breast fibroadenomas from 21-, 23- and 29-year-old patients. None of these samples showed methylation in any of the 49 CpGIs.

In order to evaluate the effect of the aberrant methylation on the level of protein expression in the fibroadenoma, we investigated the expression of ER $\alpha$ protein observing a moderate intensity in only $15 \%$ of the fibroadenoma epithelial cells (Figure 2).

\section{Discussion}

To the best of our knowledge, the only reported aberrant methylation in fibroadenomas is in gene p16INK4a. Our previous results analyzing a 49-gene regions panel which does not include the same reported CpGI of p16INK4a- have not revealed aberrant methylation in benign breast lesions $[4,5]$.

Our finding of five aberrant methylated regions in the reported GF suggests that this type of fibroadenoma presents a different etiology than other benign breast lesions, at least regarding the methylation profile.

In invasive breast tumors we have detected from two to 23 aberrantly methylated cancer-related regions, which indicates that five affected CpGIs is not a high number for a breast carcinoma (unpublished data). The surprising novelty, however, is that this finding occurs in a benign lesion.

These five aberrant methylated genes play diverse functions in the cell: DNA reparation (MGMT and BRCA2), cell cycle control (BRCA2, WT1), proliferation (WT1, ESR1) and cell adhesion (CD44). The methylation of three of them (ESR1, MGMT and WT1) has

Table 1 CpG Islands analyzed

\begin{tabular}{|c|c|c|c|c|c|c|c|c|c|c|c|c|c|c|}
\hline & Gene & Region & & Gene & Region & & Gene & Region & & Gene & Region & & Gene & Region \\
\hline 1 & $A P C$ & $-21 b p$ & 11 & $\mathrm{CDH} 13$ & $186 \mathrm{bp}$ & 21 & IGSF4 & $-56 b p$ & 31 & p73 & $+258 \mathrm{bp}$ & 41 & RASSF1 & $+46 \mathrm{bp}$ \\
\hline 2 & ATM & $+309 \mathrm{bp}$ & 12 & CHFR & -103 bp & 22 & IGSF4 & $-294 \mathrm{bp}$ & 32 & p73 & $+25 \mathrm{bp}$ & 42 & RB1 & $-226 b p$ \\
\hline 3 & ATM & $+138 \mathrm{bp}$ & 13 & CHFR & $-96 b p$ & 23 & MGMT & -463 bp & 33 & PAX5 & $-120 b p$ & 43 & RB1 & $-449 b p$ \\
\hline 4 & BRCA1 & $-20 b p$ & 14 & DAPK1 & $+527 \mathrm{bp}$ & 24 & MLH1 & $+55 \mathrm{bp}$ & 34 & PAX6 & $-52 b p$ & 44 & STK11 & $+416 \mathrm{bp}$ \\
\hline 5 & BRCA1 & $+86 b p$ & 15 & ESR1 & $+244 \mathrm{bp}$ & 25 & MLH1 & $-320 \mathrm{bp}$ & 35 & PTEN & $-813 b p$ & 45 & THBS1 & $-791 b p$ \\
\hline 6 & BRCA2 & $+221 \mathrm{bp}$ & 16 & FHIT & $+225 \mathrm{bp}$ & 26 & p15 & $+473 \mathrm{bp}$ & 36 & PTEN & $-66 \mathrm{bp}$ & 46 & TIMP3 & $+1019 b p$ \\
\hline 7 & BRCA2 & $+138 \mathrm{bp}$ & 17 & GATA5 & $+271 \mathrm{bp}$ & 27 & p16 & $-817 b p$ & 37 & PYCARD & +437 bp & 47 & $\mathrm{VHL}$ & +115 bp \\
\hline 8 & CASP8 & $+291 \mathrm{bp}$ & 18 & GSTP1 & $+148 \mathrm{bp}$ & 28 & p16 & $+200 \mathrm{bp}$ & 38 & RAR $\beta$ & $-357 b p$ & 48 & $\mathrm{VHL}$ & $-3 b p$ \\
\hline 9 & CD44 & $+411 \mathrm{bp}$ & 19 & GSTP1 & $+468 \mathrm{bp}$ & 29 & P27 & $+307 \mathrm{bp}$ & 39 & RAR $\beta$ & $-180 b p$ & 49 & WT1 & $-210 b p$ \\
\hline 10 & CD44 & $+28 \mathrm{bp}$ & 20 & $\mathrm{HIC1}$ & $-6 b p$ & 30 & P53 & $+100 \mathrm{bp}$ & 40 & RASSF1 & $-136 b p$ & & & \\
\hline
\end{tabular}

The table shows the 49 genomic regions tested during the study. Positive and negative signs are related to the transcription start base pair. 

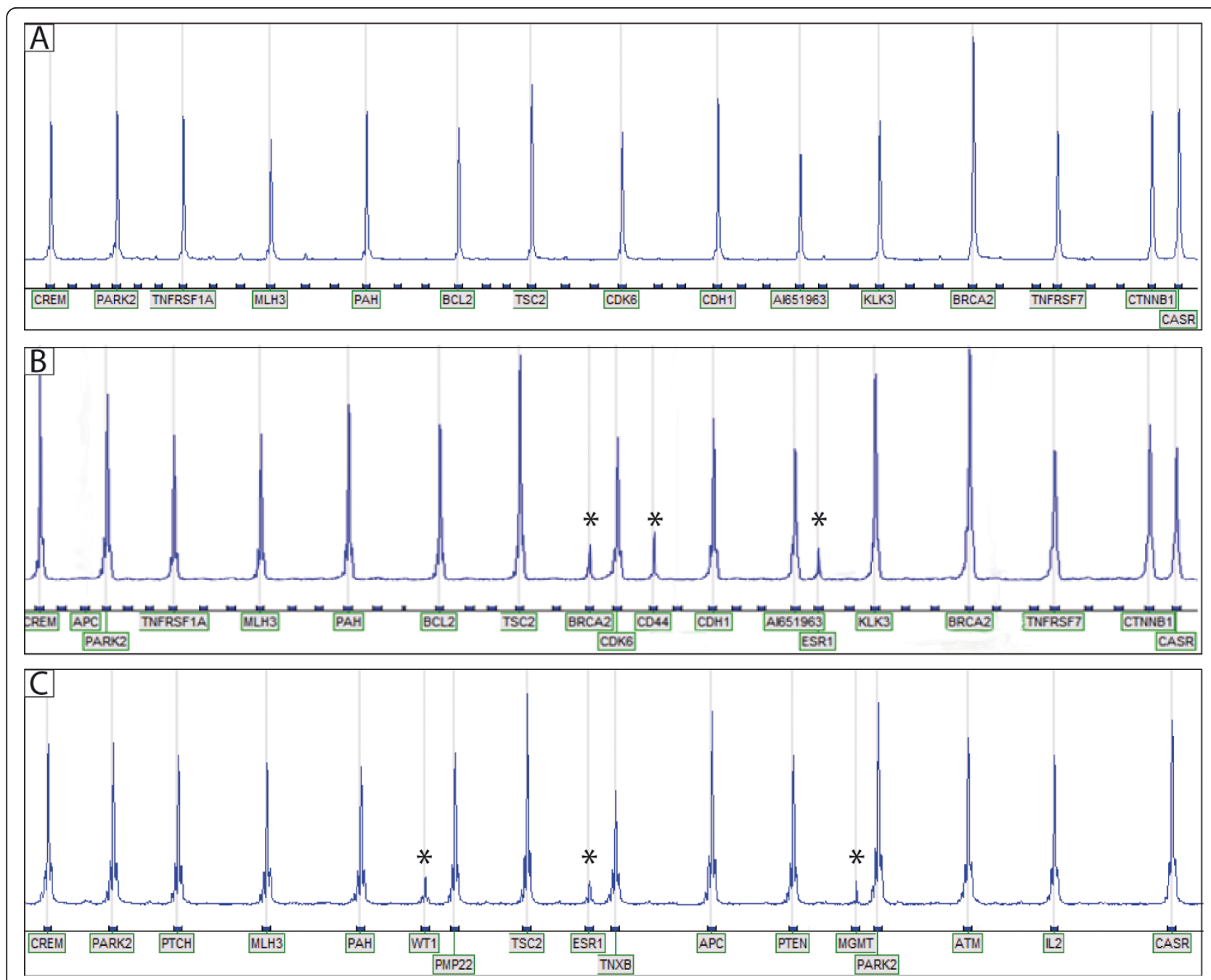

Figure 1 Detection of aberrant DNA methylation in the giant fibroadenoma. A: MS-MLPA analysis of DNA isolated from non-giant fibroadenoma. None of the analyzed regions are methylated. Only the PCR products from control probes are detected. B and C: MS-MLPA analysis of DNA isolated from the giant fibroadenoma. The methylation specific peaks are marked with an asterisk (*). Panel $\mathbf{B}$ shows the presence of methylation in BRCA2, CD44 and ESR1 genes and panel $\mathbf{C}$ shows the methylation of WT1, ESR1 and MGMT genes.

been widely reported in breast tumors $[2,4,8]$. Methylation of WT1 has not been found in normal tissue [9]. Previous studies have reported the methylation of BRCA2 in breast tumor but to the best of our knowledge, our study is the first to find methylated BRCA2 in benign breast disease [10]. Regarding gene CD44, as far as we know, its methylation status has not been reported in mammary tissue before, even though new evidence suggests its methylation in the breast cancer cell line MCF7 [11]. Methylation of the ESR1 promoter and its first exon has been observed to be correlated with loss of the expression of ER $\alpha$ receptor, even though some breast cancer specimens maintain its expression $(E R+)$ [12-14]. Tests based on ER $\alpha$ staining in fibroadenoma reveal a pronounced heterogeneity (range between 1\% and 85\%) showing no age correlation
[15]. Our specimen expresses $15 \%$ of ER $\alpha$ protein, which is considered low. Even though we are not able to establish the percentage of methylated ESR1 genes in the GF, given its heterogeneity, this low protein expression is in accordance with the determined methylated gene profile. The methylation of these five regions could be responsible in part for the high growth rate present in the analyzed GF.

\section{Conclusions}

Our data contribute to the growing knowledge of aberrant methylation in breast diseases. In this particular case there were no previously published data regarding the role of methylation in GFs, considered by definition to be a benign breast lesion. These findings should be taken into account to evaluate whether it is associated 


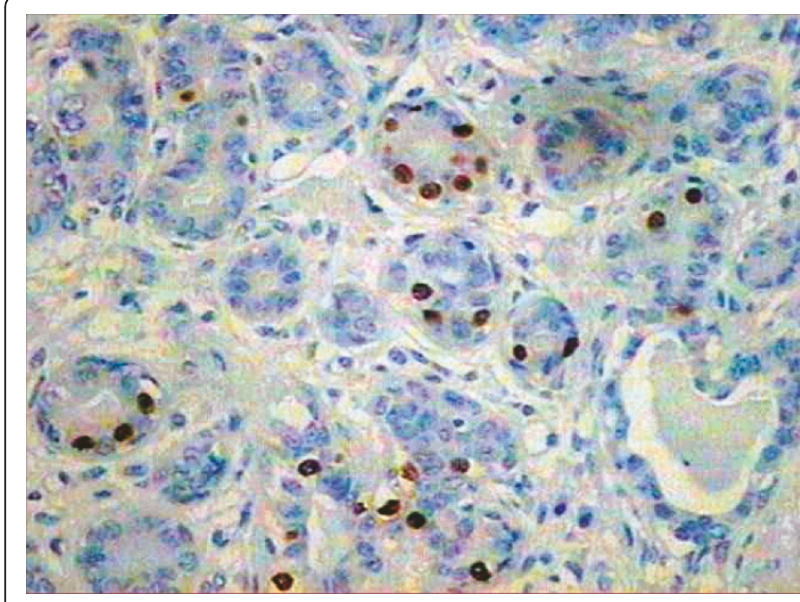

Figure $\mathbf{2}$ Immunostaining of ER $\alpha$ protein. The figure shows the staining in the nuclei of a few epithelial cells of the giant fibroadenoma (400x).

with the different etiology of non-GFs and GFs. Further studies will be necessary to draw more definitive conclusions about the meaning of the methylation de-regulation in this type of disease.

\section{Consent}

Written informed consent was obtained from the patient's next-of-kin for publication of this case report and any accompanying images. A copy of the written consent is available for review by the Editor-in-Chief of this journal.

The study was approved by the Bioethics Committee of the School of Medical Sciences, National University of Cuyo, Mendoza, Argentina.

\section{Abbreviations \\ BRCA2: Breast Cancer 2; CD44: Hermen Antigen; CpGls: CpG islands; ERa: estrogen receptor a protein; ESR1: estrogen receptor-a; GF: giant fibroadenoma; MGMT: O6-methylguanine-DNA methyltransferase; MS-MLPA: Methylation-specific multiplex ligation-dependent probe amplification; p16INK4a: Cyclin-dependent kinase inhibitor 2A; WT-1: Wilms' Tumor-1}

\section{Acknowledgements}

Funding for this study was provided by SECTyP, National University of Cuyo (06-J343) and the School of Medical Sciences, National University of Cuyo, Mendoza, Argentina.

\section{Author details}

'Cellular and Molecular Laboratory, IHEM-CCT-CONICET, Parque General San Martín s/n, CP 5500, Mendoza, Argentina. ${ }^{2}$ School of Medical Sciences, National University of Cuyo, Parque General San Martín s/n, CP 5500, Mendoza, Argentina. ${ }^{3}$ Gineco-Mamario Institute, San Lorenzo 536, CP 5500, Mendoza, Argentina. ${ }^{4}$ Tumor Biology Laboratory, IMBECU-CCT-CONICET, Avda Adrian Ruiz Leal s/n, Parque General San Martín, CP 5500, Mendoza, Argentina.

\section{Authors' contributions}

DMM performed the methylation study and revised the manuscript critically. FEG participated in the study design with JO. OT carried out the pathological studies. MR participated in interpretation of data and revised the manuscript critically. LMV-R designed the study and wrote the manuscript. All the authors discussed the results and read and approved the final manuscript.

\section{Competing interests}

The authors declare that they have no competing interests.

Received: 17 March 2011 Accepted: 18 October 2011

Published: 18 October 2011

\section{References}

1. Gobbi D, Dall'Igna P, Alaggio R, Nitti D, Cecchetto G: Giant fibroadenoma of the breast in adolescents: report of 2 cases. J Pediatr Surg 2009, 44: e39-41.

2. Agrawal A, Murphy RF, Agrawal DK: DNA methylation in breast and colorectal cancers. Mod Pathol 2007, 20:711-721.

3. Jones PA, Baylin SB: The epigenomics of cancer. Cell 2007, 128:683-692.

4. Marzese DM, Gago FE, Vargas-Roig LM, Roque M: Simultaneous analysis of the methylation profile of 26 cancer related regions in invasive breast carcinomas by MS-MLPA and drMS-MLPA. Mol Cell Probes 2010, 24:271-280.

5. Di Vinci A, Perdelli L, Banelli B, Salvi S, Casciano I, Gelvi I, Allemanni G, Margallo E, Gatteschi B, Romani M: p16(INK4a) promoter methylation and protein expression in breast fibroadenoma and carcinoma. Int J Cancer 2005, 114:414-421.

6. Chintamani , Khandelwal R, Tandon M, Yashwant K, Kulshresthal P, Aeron T, Bhatnagar D, Bansal A, Saxena S: Carcinoma developing in a fibroadenoma in a woman with a family history of breast cancer: a case report and review of literature. Cases Journal 2009, 2:9348.

7. Vargas-Roig LM, Cuello-Carrión FD, Fernández-Escobar N, Daguerre P, Leuzzi M, Ibarra J, Gago FE, Nadin SB, Ciocca DR: Prognostic value of Bcl-2 in breast cancer patients treated with neoadjuvant anthracycline based chemotherapy. Molecular Oncology 2008, 2:102-111.

8. Munot K, Bell SM, Lane S, Horgan K, Hanby AM, Speirs V: Pattern of expression of genes linked to epigenetic silencing in human breast cancer. Hum Pathol 2006, 37:989-999.

9. Loeb DM, Evron E, Patel CB, Sharma PM, Niranjan B, Buluwela L, Weitzman SA, Korz D, Sukumar S: Wilms' tumor suppressor gene (WT1) is expressed in primary breast tumors despite tumor-specific promoter methylation. Cancer Res 2001, 61:921-925.

10. Cucer $N$, Taheri $S, O k E$, Ozkul Y: Methylation status of $\mathrm{CpG}$ islands at sites -59 to +96 in exon 1 of the BRCA2 gene varies in mammary tissue among women with sporadic breast cancer. J Genet 2008, 87:155-158.

11. Müller I, Wischnewski F, Pantel K, Schwarzenbach H: Promoter- and cellspecific epigenetic regulation of CD44, Cyclin D2, GLIPR1 and PTEN by methyl-CpG binding proteins and histone modifications. BMC Cancer 2010, 10:297.

12. Ottaviano YL, Issa JP, Parl FF, Smith HS, Baylin SB, Davidson NE: Methylation of the estrogen receptor gene CpG island marks loss of estrogen receptor expression in human breast cancer cells. Cancer Res 1994, 54:2552-2555.

13. Lapidus RG, Ferguson AT, Ottaviano YL, Parl FF, Smith HS, Weitzman SA, Baylin SB, Issa J-PJ, Davidson NE: Methylation of estrogen and progesterone receptor gene $5^{\prime} \mathrm{CpG}$ islands correlates with lack of estrogen and progesterone receptor gene expression in breast tumors. Clin Cancer Res 1996, 2:805-810.

14. Hori M, Iwasaki M, Yoshimi F, Asato Y, Itabashi M: Determination of estrogen receptor in primary breast cancer using two different monoclonal antibodies, and correlation with its mRNA expression. Pathol Int 1999, 49:191-197.

15. Shoker BS, Jarvis C, Clarke RB, Anderson E, Munro C, Davies MPA, Sibson DR, Sloane JP: Abnormal regulation of the oestrogen receptor in benign breast lesions. J Clin Pathol 2000, 53:778-783.

doi:10.1186/1752-1947-5-516

Cite this article as: Marzese et al.: Aberrant DNA methylation of cancerrelated genes in giant breast fibroadenoma: a case report. Journal of Medical Case Reports 2011 5:516. 